\title{
Construction of the Olympic Games Visual System Model
}

\author{
Dong $\mathrm{Yu}$ \\ Physical Department of \\ Harbin Engineering University, Harbin, \\ Heilongjiang, China \\ aDongyu@hrbeu.edu.cn
}

\begin{abstract}
Nowadays, the Olympic Games is the most charming social cultural phenomena, one mainly reason is that it creates the distinctive and unique Olympic visual effectiveness. The Olympic visual effectiveness is the representation of the content of the Olympic Games, the inheritance and development of the humanity traditions of the Olympic Games, comprehensive integrity and artistic expression of the Olympics' notion and essence. During the process of the design, we will take the methods of collecting the files, analyzing systematically, evaluating comprehensively, and interviewing and computer application. From the above statements ,we can know that the systematic study of the Olympic visual effectiveness, the overall and vivid constitution of the model will enrich the realistic meaning of the theory, and at the same time offer important reference for he image of the sports and the design of the image of international events which is under the cross-cultural spreading background.
\end{abstract}

\section{Keywords- Olympic Games; Visual System; Model}

\section{INTRODUCTION}

The design of Olympic visual images not only the pursuit of Olympicsm of the hosting countries and areas that use their own way of expressing, but the window to show Olympic culture, global culture and modern arts and design levels. The research of Olympic visual system contains fundamental elements and applicable elements. Utilizing physics, aesthetics, philosophy, sociology, history and geography to analyze systematically, it classifies and concludes each item deliberately and provides complete data base and powerful reference function.

\section{ORGANIZATION OF THE TEXT}

A. Dividing principles of the content of Olympic visual system

Olympic visual system, the visual identity of Olympic Games, is the outward manifestation of Olympic connotation, which uses graphic design and visual communication design to express the Olympic concepts conducts. The fundamental elements and applicable elements need further detailing, in order to highlight the function, distinct the image and enlarge the economic efficiency.

B. The dividing standards of graphic elements and applicable materials
TABle 1 Distribution of Olympic Visual SySTEM ElEMENTS

\begin{tabular}{|c|c|c|c|c|}
\hline $\begin{array}{l}\text { Olympic } \\
\text { Elements }\end{array}$ & \multicolumn{2}{|c|}{$\begin{array}{l}\text { Fundamental } \\
\text { Elements }\end{array}$} & \multicolumn{2}{|c|}{ Applicable Elements } \\
\hline $\begin{array}{l}\text { Dividing } \\
\text { Standards }\end{array}$ & $\begin{array}{l}\text { Graphic } \\
\text { Elements }\end{array}$ & $\begin{array}{c}\text { Applicable } \\
\text { materials }\end{array}$ & $\begin{array}{l}\text { Graphic } \\
\text { Elements }\end{array}$ & $\begin{array}{c}\text { Applicable } \\
\text { materials }\end{array}$ \\
\hline Content & $\begin{array}{l}\text { 1.Olympic } \\
\text { Symbols } \\
\text { 2.Olympic } \\
\text { Emblem } \\
\text { 3. Biding } \\
\text { Symbols }\end{array}$ & $\begin{array}{l}\text { 1. Mascot } \\
\text { 2. Olympic } \\
\text { Torch } \\
\text { 3.Olympic } \\
\text { Medals }\end{array}$ & $\begin{array}{l}\text { 1.Propaganda } \\
\text { diagram } \\
\text { 2.Physical } \\
\text { events diagram } \\
\text { 3.Traffic } \\
\text { identification } \\
\text { 4. } \\
\text { Environmental } \\
\text { signage }\end{array}$ & $\begin{array}{l}\text { 1. Papers } \\
\text { 2,Entrance } \\
\text { tickets } \\
\text { 3. Souvenir } \\
\text { 4. Mails } \\
\text { 5.Office } \\
\text { supplies } \\
\text { 6. } \\
\text { Buildings }\end{array}$ \\
\hline
\end{tabular}

C. Dividing standards of hosting category, hosting time and hosting countries

Olympic Games mainly contain Winter Olympic Games and Summer Olympic Games. Though they have the same concept, function and cultural inheritance value, there are obvious differences in counties and times. According to different times, seasons and climate, different visual communication methods and concept expression have their unique features. Defining symbol properties, they interpret the design concepts and communication meanings of all kinds of symbols and applicable objects in Olympic visual images. Furthermore, host cities' properties and advantages could be analyzed deliberately. To analyze the geographical advantages of the host cities from the geography angle, it provides inspiration for bidding and hosting Olympic Games.

\section{Dividing standards of different visual elements}

The construction of Olympic visual system, from the abstract icons to concrete objects, is the carrier of Olympic concepts. It is also a shortcut to research from various visual elements, but it should place extra emphasis on research pointcuts and subject choice. To divide reasonably of the research targets, the dividing standards of the context 
and pointcut are as following:

TABLE 2 DiVISION OF OLYMPIC ViSUAL SYSTEM ACCORDING TO RESEARCH POINTCUT AND SUBJECTS

\begin{tabular}{|c|c|c|c|}
\hline $\begin{array}{l}\text { Olympic } \\
\text { Elements }\end{array}$ & Visual & $\begin{array}{l}\text { Research } \\
\text { Pointcut }\end{array}$ & Subject Choice \\
\hline \multirow[b]{3}{*}{$\begin{array}{l}\text { Basic } \\
\text { Elements }\end{array}$} & Graph & Inheriting & \multirow[b]{2}{*}{$\begin{array}{l}\text { Sports history, } \\
\text { history, aesthetics }\end{array}$} \\
\hline & $\begin{array}{l}\text { ic } \\
\text { Elements }\end{array}$ & $\begin{array}{l}\text { ideas and design } \\
\text { concepts }\end{array}$ & \\
\hline & $\begin{array}{l}\text { Mater } \\
\text { ial } \\
\text { Elements }\end{array}$ & $\begin{array}{l}\quad \text { Design } \\
\text { concepts, } \\
\text { appearance } \\
\text { molding, material } \\
\text { quality }\end{array}$ & $\begin{array}{l}\quad \text { Sports } \\
\text { ethnology, } \\
\text { designing, } \\
\text { science }\end{array}$ \\
\hline cable ${ }^{\text {Appli }}$ & $\begin{array}{l}\text { Graph } \\
\text { ic } \\
\text { Elements }\end{array}$ & $\begin{array}{l}\text { Item } \\
\text { classification } \\
\text { feature, publicity } \\
\text { ideas }\end{array}$ & \multirow{2}{*}{$\begin{array}{l}\quad \text { Advertising } \\
\text { communication, } \\
\text { semiology, sports } \\
\text { science } \\
\quad \text { Communication } \\
\text { theory, graphic design, } \\
\text { architecture }\end{array}$} \\
\hline Elements & $\begin{array}{l}\quad \text { Mater } \\
\text { ial } \\
\text { Elements }\end{array}$ & \begin{tabular}{l}
\multicolumn{2}{c}{ Practical } \\
value, publicity \\
ideas
\end{tabular} & \\
\hline
\end{tabular}

\section{CONSTRUCTION OF THE OLYMPIC GAMES VISUAL} SYSTEM THEORY FRAME

From simple graphic elements to complicate mixed pictures, or from a delicate stamp to a charming torch, all those construction activities of the Olympic Games visual system demonstrate Olympic philosophy, Olympic sense of worth and Olympic esthetic sentiment. From simple to complicate, casual to unified, similar to creative, every element of the Olympic Games visual system experienced a special development process.

\section{A. Main Frame of the Construction of the Olympic Games Visual System Model}

In the process of construction of the Olympic Games visual system, it is necessary to clarify the direction of the research and find a clear clue to build up the model theory frame. In search of the model theory frame of the Olympic Games visual system, the first thing should be concerned is the origin and purpose of Olympic Games, and then is the Olympic thinking system because Olympic thinking is the motivity and foundation of the construction of the Olympic Games visual system(Figure 1).

\section{B. Subframe of the Construction of the Olympic Games Visual System Model}

\section{Research on the Fundamental Elements of the Olympic Games Visual System}

When the main frame of the construction of the Olympic Games visual system model formed, its subframe will be built up according to it. The subframe comes from the main frame and share the same design concept and theme with it. At the same time, every subframe can be divided into more detailed branches. The prime symbols can be Olympic symbol, Olympic Emblem, Olympic Medals and Olympic Mascot, and all those symbols can demonstrate the unique visual effects of Olympic Games and exert influence on the society.

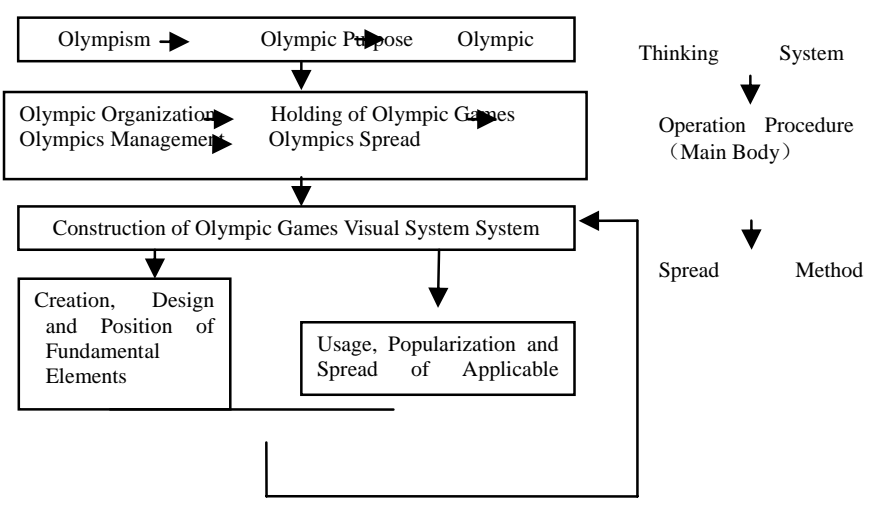

Figure 1 MAIN Frame OF THE CONSTRUCTION OF THE OLYMPIC GAMES VISUAL SYSTEM MODEL

Olympic rings is the core symbol of Olympic Games visual image and embodied in other emblems, symbols and patterns with different extents. The design of the main body of Olympic emblem often can show the special cultural connotations of different stages, different peoples and different regions. In the previous research on Olympic emblem, many scholars divided the development period of Olympic emblem into four stages: rudiment period (1896-1924), transition period (1924-1928), formative period (1932-1968) and maturity period (1972- ). Many representative patterns such as people, animals, plants, environments, architectures and sports were added into the design of the previous Olympic emblems. According to the propaganda angles and needs of different hosting countries, designs of Olympic emblems are different with distinct imagination.

Olympic medal shares some similarity with Olympic emblem in research field. However, they have different spread methods and concepts as well. The style of Summer Olympic Games medals is simple but also can be divided into four stages because there are some obvious demarcation points in its development process, that is: rudiment period(1896-1924), stationary period(1928-1968), transform period(1972-2000) and developing period(2004-). In short, the design of Winter Olympic Games medals experienced a process from simple to complicate and simple again, from ancient to modern and to more innovative, from entity to abstract and from flat to solid. According to that, the development process of Winter Olympic Games medals can be divided into four stages: rudiment period(1924-1936), revivification period(1948-1964), developing period(1972-1988) and maturity period(1992-).

Olympic mascot is one of the main elements in the Olympic Games visual system. The three questions should be concerned firstly when researching the visual effects of Olympic mascot are the choice of Olympic mascots, the value of Olympic mascots and the symbolic meaning of Olympic mascots.

D. Research on Application System of the Olympic Visual 


\section{System}

The main symbols of the visual images of all the previous Olympic Games are the main tone and the main theme of the Olympic theme. The best means of propagating the visual system is to apply the main symbols to various fields and industries, thus can we do better in spreading the Olympic spirits and advertizing the host country. The application system of the Olympic visual system mainly includes sports item icons, environment logos, medals, commemorative coins and posters, etc. These application designs are completed according to the graphics, texts and colors of the logo of the Olympic Games, thus achieving the ultimate goal of decorating the Olympics and embodying the hosting concepts.

The Olympic posters, one of the cultural communication projects to which close attention are paid by all previous host countries of the Olympic Games. For the purpose of carrying forward the Olympic spirits, unique visual impact advantages have been formed through original design and theme planning. Vivid and readable, the Olympic posters, which are with both excellent pictures and texts, are delivering the concepts of the Olympic Games.

From the Athens Olympics, designing and producing Olympic medals and commemorative coins has become customary, and in each sessions of the Olympic Games, a lot of medals and commemorative coins are made as the most representative souvenir of this session[9]. With the improvement of the artistic quality of the Olympic medal design, more and more countries realize that the artistic value of the medals and commemorative coins is helpful to the cultural pursuit of the Olympics, and they are also able to be brought into circulation, where there is the necessity of commercial operations.

Olympic public logos can be classified into sports logos, environmental logos and indicative logos, etc. Sports logos are mainly to stress the species of sports and try to portray the sports by simple patterns. Environmental logos are the graphic description of some basic information like the location of some buildings, road signs and gymnasia and so forth. There are many different kinds of Olympic public logos with different styles.

\section{LEARNING PLATFORMS OF OLYMPIC GAMES VISUAL SYSTEMS CONSTRUCTED BASED ON COMPUTER} TECHNOLOGIES

\section{A. Production of Searching Engineers of Materials Storehouse}

Olympic culture is a comprehensive and complete theoretical system. All previous Olympic Games has provided for according accessible information as a sole approach to understand the connotation of diversified cultures. However there are not a series of materials storehouse software which can be used to search words materials, pictures and even video materials whenever consulters and learners intend to.

The production of material storehouse can be completed with the aid of simple software such as Authoware and Director for the production of courseware, whose procedures are follows: 1) collecting materials; 2) sorting out materials; 3) producing software frames; 4) stuffing materials; 5)software testing; 6) formal operation of software. What should be paid more attention to is recognizing whether or not the materials can be put into wide use, and how much space they would occupy during the process of software production. Meanwhile it should also be taken into consideration that whether or not software is so effective that learners could conveniently and accurately find out their needed information while key words are inserted.

\section{V.THE PRODUCTION OF 2D OR 3D MATERIALS}

STOREHOUSE AS TO BASIC ELEMENTS OF OLYMPIC VISUAL SYSTEM

The construction of Olympic visual system models is creative in that it can make 2D or 3D material storehouse, set up serial programs, and every independent material storehouse can be randomly applied to any courseware or internet platforms. For instance medals in two-dimensioned animation can be made by CAD technologies and flash software

It is with the aid of CAD technologies and flash software that medals can have the effect of two-dimensional motive animation for the sake of practical observation and appreciation. And the production of torches and mascots can only achieve three-dimensional effects in the method of 3D MAX software and CAID technologies, which can be whirled and deformed at random to enhance the color and luster as well as tactile impression.

\section{A. The Production of Internet Learning Platforms}

Internet learning platforms which can be easily mastered and employed are constructed through computer technologies based on the theoretical frame of the comprehensive Olympic visual system. The set-up of platforms should take two aspects into account: one is they are supposed to be of user-friendly various functions; another is rich in information covering extensive fields. If learning platforms can reach these objectives, they will not only become an important reference tools for studies of Olympic cultures, but also function as the large and complete database system for the future development of Olympic visual systems.

\section{SUMMARY}

Construction of the Olympic Games visual system model has attached importance to the exploration of the cultural connotation of the Olympic Games visual images so that it can be established in a fundamental, specific and detailed manner. Simultaneously concerning the perspective of the science of sporting, the model will become an indispensable theoretical resource for the studies of the Olympic Games culture and is capable of illustrating its profound value so as to make contribution to its inheritance and development. Studies on all previous Olympic visual massages and all design concepts of visual images has been conducted in a way of classifying all elements of visual systems according to their specific laws and rules and then 
selected a breakthrough point to establish main frames and sub-frames with the help of relevant subjects. Consequently the material storehouse and simulated learning platforms of the Olympic Games visual system can be constructed by employing relevant software technologies so as to create a novel idea to study the Olympic culture.

\section{ACKNOWLEDGEMENTS}

In 2013 the Ministry of Education of Humanities and Social Science Youth Fund Project (13YJC890013);

In 2011 Philosophy Social Science Research Projects of Heilongjiang Province (Sports) (11D095);

Harbin Engineering University Fundamental Research Funds for the Central Universities Key Projects (HEUCF111601)

\section{CORRESPONDING AUTHOR}

Yu Dong, Physical Department of Harbin Engineering University, Harbin, Heilongjiang, China, 13946017987

\section{REFERENCE:}

[1] Xiumin, Kong, Research of Olympic Culture, People's Sports Publishing House of China, Beijing (2006).

[2] Wei Hu, History Dynamic State of the Olympic Game Badge Spirit, Journal of Xi'an Physical Education University, 2007. 3(24), p. 28-31

[3] A.W.Vatleskin, W.L.Stein Bach, Olympic Medals, Badges and Posters, Shandong Pictorial Publishing House, Shandong (2005).

[4] Jim Greenfield, Orgler Vorontsov, Jim Larry, Olympic Medals (1896-2008), People's Sports Publishing House of China, Beijing (2008). 